\title{
As políticas de desenvolvimento entre a sedução e a sedação
}

\section{The politics of development between seduction and sedation}

\section{Las políticas de desarrollo entre la seducción y la sedación}

iD Guilherme Francisco Waterloo Radomsky

Universidade Federal do Rio Grande do Sul, Porto Alegre, Rio Grande do Sul, Brasil guilherme.radomsky@ufrgs.br

Resumo: O trabalho analisa a relação entre agricultores ecologistas e o Estado, no oeste de Santa Catarina, através da ação de mediadores. Dois aspectos dessa conexão são examinados. Primeiramente, o espaço de atuação e o poder dos mediadores estabelecendo articulações entre os diferentes níveis da ação estatal (federal, estadual e local) e as organizações. Em segundo lugar, o tema do desenvolvimento e o Estado na condução de políticas e programas de intervenção. Resultados de pesquisa de campo de orientação etnográfica - conduzida entre 2008 e 2009 - sustentam, por um lado, que os mediadores possuem papel capital ao preencherem espaços potencialmente dinâmicos, estabelecendo relações e construindo formas de promoção da agricultura. Por outro lado, a investigação mostra que, a partir deste amálgama de relações, o Estado é interpretado de modo ambivalente entre o desejo e a repulsa por parte dos agricultores, portanto cobrado por ações e simultaneamente avaliado por intervenções problemáticas.

Palavras-chave: Mediação. Agroecologia. Desenvolvimento rural. Violência. Estado.

Abstract: The paper analyzes the relationship between organic farmers from western of Santa Catarina state (Brazil) and the State 
through the action of mediators. Two aspects of this connection are examined. Firstly, the performance space and the power of brokers for establishing links between different levels of government action and the society organizations. Secondly, development processes and the role of the State towards policies and intervention programs. Results of ethnographic fieldwork research - between 2008 and 2009 - show that mediators occupy a relevant role to fulfill potentially dynamic spaces, making connections and building ways to support agriculture. On the other hand, the research also demonstrates that, from this peculiar sort of relationships, the State is interpreted ambivalently between desire and repulsion by farmers; therefore, the State is charged for actions and simultaneously criticized for problematic interventions.

Keywords: Brokerage. Agro-ecology. Rural development. Violence. State.

Resumen: El artículo examina la relación entre los agricultores ecologistas del oeste del estado de Santa Catarina (Brasil) y el Estado a través de la acción de mediadores. Se examinan dos aspectos. En primer, el espacio de atuación y el poder de los mediadores que crean vínculos entre los diferentes niveles de gobierno (nacional, estatal y local) y las organizaciones sociales. En segundo, los procesos de desarrollo y el rol del Estado en la conducción de las políticas y programas de intervención. Resultados de investigación de campo - entre 2008 y 2009 - sostienen, en primer lugar, que los mediadores tienen papel fundamental en los espacios potencialmente dinámicos, creando y articulando relaciones y construyendo mejores programas para la agricultura. Por otro lado, la investigación también muestra que, a partir de estas conexiones, el Estado es interpretado de manera ambivalente entre el deseo y la repulsión por los agricultores. Aunque les cobran por las acciones estatales, simultaneamente el Estado es criticado por sus intervenciones problemáticas.

Palavras clave: Mediación. Agroecología. Desarrollo rural. Violencia. Estado.

Data de recebimento do artigo: 9/10/2019

Data de aprovação do artigo: 17/01/2020 


\section{Introdução}

Após alguns meses realizando pesquisa entre agricultores ecologistas no oeste de Santa Catarina, e já com dados bastante ricos para a análise que eu inicialmente pretendera, percebi que havia uma negligência no trabalho de investigação a ser corrigida. Embora o foco da pesquisa de campo estivesse concentrado na agricultura ecológica (seus constituintes simbólicos e as articulações políticas entre agricultores, mediadores e consumidores), quase não concedi devida atenção às relações dos pequenos proprietários rurais ecologistas com o Estado durante o período inicial de investigação de campo. Ao verificar essa lacuna - não a única, mas importante -, compreendi que havia uma razão suficientemente explicativa: ao conviver com os interlocutores em campo, o que conseguia apreender da representação acerca do Estado por parte deles era instável, além de não me dar subsídios para ter certeza do que eu então escutava. Essa foi uma das razões, percebi depois, pela qual me concentrei mais em outros problemas ao longo da pesquisa.

Se o conhecimento em antropologia é uma relação entre as cosmovisões de pesquisador-interlocutor, conforme Viveiros de Castro (2004), a instauração de um processo cognitivo depende, pelo menos, de uma clareza parcial a respeito do que se forma discursivamente nesse diálogo. Compreendo que este pode ser o princípio de um projeto de ciência social reflexiva proposta por Goldman (2008) em que a resistência que colocamos à palavra "nativa" encontra paralelos àquela que o "nativo" coloca à palavra inquisitiva do pesquisador. Nessa situação a chamar a atenção, parafraseando Dawsey (2007), em argumento emprestado de Geertz: não seriam as elipses, emendas suspeitas e incoerências os sinais de que algo revelador se apresenta para nós?

De que se trata tal mudança de posição dos atores em relação ao Estado? Se em certas ocasiões os agricultores manifestavam 
atração pelas ações do Estado e suas formas de intervenção social, em outras a aversão é que tomava conta dos sentimentos. Entre uma e outra, meias palavras e sentimentos não transparentes emergiam. À medida que o tempo passou, outros pares de oposição e seus meios-termos apareceram e serão aqui debatidos e analisados. Antes de refletir sobre essas conexões e disjunturas, cabe dizer poucas palavras sobre o que mais esta aparentemente espontânea relação permitiu à pesquisa.

Caso seja possível admitir que a relação das pessoas com o Estado se configura como um tema tão amplo que dificilmente possa ser tratado sem um foco específico, a pesquisa de campo direcionou a investigação a dois elementos articulados. Primeiramente, o espaço de atuação de mediadores no entre-lugar da relação dos agricultores ecologistas (geralmente pequenos proprietários rurais) com o Estado e estabelecendo conexões de setores estatais nos níveis federais, estadual e local com organizações de representação político-sindical local; em segundo, no tocante ao tema do desenvolvimento e o papel que é atribuído ao Estado para tal fim.

Assim, a finalidade deste artigo consiste em, em primeiro lugar, descrever e compreender a atuação dos mediadores, salientando aspectos particulares que emergem da relação entre agricultores ecologistas, organizações sociais e o Estado; e, em segundo lugar, examinar a representação do Estado por parte das pessoas envolvidas nestes processos, especialmente agricultores ecológicos da região, procurando focar nas dimensões ambivalentes em suas avaliações a respeito do ente estatal. Isto conduzirá a uma reflexão sobre o Estado e a literatura acerca de programas e políticas de desenvolvimento, e outras relacionadas, que aportem contribuições para uma leitura sobre os processos sociais em questão.

A pesquisa de caráter etnográfico foi conduzida entre agricultores - da Rede Ecovida de Agroecologia -, mediadores e consumidores de alimentos ecológicos, entre 2008 e 2009, na região de Chapecó no estado de Santa Catarina, Brasil. Circulei por diversos pequenos municípios para entrevistas, observações em feiras e 
reuniões dos grupos de agricultores e consumidores, porém foi em Chapecó que dediquei maior parte do tempo de pesquisa e, por isso, será a localidade que terá mais espaço nas descrições e análises. Chapecó localiza-se na região oeste do estado de Santa Catarina, Brasil, estando na divisa com o estado do Rio Grande do Sul e trata-se da maior cidade da região. É uma região de significativa presença de agricultores familiares e também de coletivos indígenas, tendo passado por muitos ciclos de produção agrícola durante o século XX, período que testemunhou maior crescimento populacional.

A partir de meados do século XX, a modernização da agricultura foi bem implementada mesmo entre agricultores com pequenas propriedades, tendo permanecido também no ideário do tecido social local. Mas foram os processos relacionados às grandes agroindústrias para produção de carnes de suínos e frangos os que transformaram muito as formas de trabalho e produção dos agricultores (ROVER, 2007), levando a uma integração verticalizada (MIOR 2005). Foi nesse contexto que, no final da década de 1990, as iniciativas agroecológicas tiveram início.

No que segue, examino a mediação enquanto tal e, mais adiante, como os agricultores observam, descrevem e avaliam as intervenções do Estado de modo ambivalente. Ao final, algumas considerações são traçadas.

\section{Mediação: articulação, conexão e tradução}

O que denomino de mediadores, com base no estudo das redes de agricultura ecológica em Santa Catarina, especialmente tomando o caso da Ecovida, não é um grupo especializado e à parte. Há pessoas envolvidas em Organizações não-governamentais, funcionários do Estado, agricultores líderes, docentes de instituições na região e pessoas de outros segmentos, que em geral se envolvem também com o debate sobre consumo ecológico. Tomando como 
As políticas de desenvolvimento entre a sedução e a sedação

Guilherme Francisco Waterloo Radomsky

referência estudos sobre mediação e corretagem (SARDAN, 1995; WOLF, 2003, NEVES, 2008; STOVEL e SHAW, 2012'1), não se deve atribuir características de fixidez e circunscrição a esse "grupo", talvez funcionando mais próximo de um quase-grupo (MAYER, 1987). A configuração de suas fronteiras se modifica de tempos em tempos.

Os mediadores fazem a intermediação entre o que acontece em termos de política e programas sobre ecologia nos planos internacional e nacional e o que se passa no seu raio de atuação. Acaba ficando sob sua responsabilidade também a animação das atividades, dar condições de interpretação às regras de produção de orgânicos, submissão de projetos a agências, organização e liderança nos encontros dos coletivos, ajuda na constituição de núcleos (quando é o caso) e divulgações variadas do campo. Valoriza-se nos grupos a horizontalidade, embora saibamos das dificuldades de não se produzirem distinções em quaisquer situações sociais. Ainda que isto sempre ocorra - e mais adiante volto ao problema -, um dos pilares das formas participativas de organização reside na democracia como prática e horizonte.

Nos eventos regionais, à medida que se acompanha os atores em suas interações, é corriqueiro que os mediadores e as lideranças em geral lembrem os demais sobre a necessidade do compromisso junto ao grupo. Esse compromisso diz respeito tanto à agroecologia ${ }^{2}$ - suas normas e critérios - quanto à participação nas reuniões. Sem esta, não há grupo e tampouco responsabilidade em rede pela produção e pela certificação. Debate-se recorrentemente nas reuniões quem está e quem não está andando junto ao grupo, isto é, em consonância aos princípios. É comum que haja, uma vez ou outra, troca de acusações, muitas vezes um tanto disfarçada, mas que aponta para os agricultores problemáticos. Na Ecovida, os mediadores agricultores possuem funções tanto intra

\footnotetext{
1 Recorro neste trecho a algumas referências que considero relevantes para este trabalho, embora a literatura antropológica sobre o tema seja vasta, pois é assunto antigo nas ciências sociais. Algumas outras referências podem interessar ao leitor, tais como Gouldner (1977), Velho e Kuschnir (1996), Silverman (1967) e Barnes (1987).

2 Os termos agroecologia e agricultura ecológica parecem eventualmente intercambiáveis. Isto não denota desconhecimento da minha parte sobre a história de debates que cada expressão testemunhou. Essa escolha foi realizada com base nas entrevistas com agricultores que se diziam (por vezes insistentemente) agroecológicos ou agroecologistas, polemizando propositadamente com técnicos, agrônomos e demais profissionais que advogam o termo somente para o âmbito da ciência. Para mais esclarecimentos, ver Assis e Romeiro (2002).
} 
como extra-grupo. São eles que se veem responsáveis pelo andamento das atividades dos núcleos, contudo igualmente lhes cabe serem enérgicos internamente; é claro que essa responsabilidade é compartilhada, portanto, sabe-se que está no próprio regime de trabalho da Ecovida essa dinâmica de controle.

Como era de se supor, do Estado e das ONGs espera-se uma mediação tipicamente profissional, conforme denomina Neves (2008), e, embora sejam os agricultores os agentes mais ativos, problemas acabam ocorrendo. Uma dirigente de associação salientou em entrevista um relato que escutou de um colega seu, também produtor familiar ecológico: "Nós construímos as entidades, nós fizemos; os agricultores estavam à frente, mas, no final, os projetos serviram para pagar diárias e viagens de técnicos". Ao recordar das palavras do colega para me transmitir, prossegue dizendo, quase em tom de gabolice, que "depois, nós não somos convidados para [...] falar nos eventos". Aqui, a questão sugestivamente faz ecos à já conhecida problemática exposta por Gayatri Spivak (2010) e a impossibilidade de fala de quem é considerado subalterno. Trata-se então da forma como percebi em campo a constituição da mediação por parte dos agricultores ecológicos, vista como tentativas de superar tal condição de subalternidade, 0 que é politicamente relevante, pois envolve diretamente o papel e a expectativa que se tem do Estado.

A partir dos estudos de Olivier De Sardan (1995) nos países africanos, Medeiros e Marques (2012) demonstram que projetos de desenvolvimento rural colocam atores em arenas nas quais as relações entre entes externos e internos podem ser conflituosas. Enquanto os agentes que querem operar iniciativas para desenvolvimento rural, muitas vezes lotados em organizações públicas, utilizam uma linguagem-desenvolvimento, esta não dialoga bem com a linguagem local (Medeiros e Marques, 2012). No caso das entidades do oeste catarinense, a linguagem-desenvolvimento (isto é, dominar os códigos dos projetos, os valores e os interesses compartilhados por agentes do Estado e das ONGs) é apropriada pelos agricultores líderes, embora os coloque num espaço "fron- 
teiriço", realizando articulação entre esfera pública mais ampliada e as comunidades rurais.

Em certas situações, a mediação assume importância pelo fato desses indivíduos se movimentarem pelas comunidades rurais, encontrando os agricultores em suas casas. Menos que a dimensão técnica, aqui entra em jogo o problema da relação em si mesma. Levar novidades aos que permanecem muito tempo trabalhando isolados importa, porém, é a interação, estar presente, que conta de fato. A este processo, poderíamos interpretar aproximando-se da noção de "agir em diversos mundos", proposta por Dodier (1993) e, em um panorama teórico diferente, apoiado na noção de metamorfose, por Velho e Kuschnir (1996), pois são essas as pessoas capazes de circular em esferas de negociação política, de articulação com associações ou cooperativas e que são facilmente recebidas pelos agricultores mais isolados.

Tema importante na obra de Eric Wolf (2003), a mediação depende deste atributo de tradução entre cenários distintos e a possibilidade dos mediadores estabelecerem ligações de comunidades semifechadas com o restante da sociedade (WOLF, 2003). Aqui cabe uma observação: as comunidades de agricultores ecológicos não são fechadas, mas todo círculo de famílias rurais tende a apresentar pessoas com mais habilidades ou vontades de estabelecer ligações entre o grupo e os de fora, numa espécie de rompimento parcial dos limites que as circunscrevem. Comunidade, portanto, é entendida aqui menos como territorialmente delimitada e semi-isolada e mais como um conjunto simbólico de relações de proximidade, empatia e intenções similares.

Apesar de as organizações se esforçarem por este trabalho de animação nas comunidades e por manterem as comunidades de agroecologistas em contato, são os agricultores líderes que assumem importância. Quanto a estes últimos, os sistemas de prestígios entre produtores premiam os que possuem capacidade de organizar os grupos, de falar bem em público e, igualmente, têm habilidade no manejo sustentável e são convictos da importância da agroecologia. Conforme foi observado por Neves (2008), na 
As políticas de desenvolvimento entre a sedução e a sedação

Guilherme Francisco Waterloo Radomsky

agricultura ecológica parece existir uma junção entre a trajetória individual, biográfica, que dá direitos localmente legitimados para os agricultores líderes, e o caráter pragmático da capacidade de circular em diferentes mundos/esferas com habilidade política. A capacidade dos agricultores ecológicos de prestígio se dá em duas frentes, ao final: na forma de participação em instâncias decisórias ou associações, bem como na interpelação dos membros do grupo; e na forma de fazer circular os saberes adquiridos em agroecologia por sua própria experiência ou nas diferentes situações em que são também aprendizes - não somente das técnicas, mas também dos aparatos de certificação³.

Esses elementos sustentam que, embora as organizações tenham importância, há um conjunto de atividades cotidianas que embasam a mediação feita pelos próprios agricultores. Acaba ocorrendo que até nestes casos os líderes são vistos pelos pares de uma maneira um pouco diferente dos demais produtores, ainda que pertencentes aos grupos, assumindo uma posição de mediadores. As organizações não abrem mão de sua relação profissional com a mediação para a agricultura ecológica, mas essa situação sugere algo semelhante ao proposto por De Vries (2002) sobre o caso rural mexicano: a de que a mediação implica uma constante recorrência de "espaços vazios" e sua ocupação momentânea entre o Estado (suas organizações, empresas públicas de extensão rural, universidades etc.) e os atores sociais. Nesta problemática sociológica, vale recuperar o que tem se escrito a partir da noção de margens do Estado. O trabalho de Das e Poole (2004), agora amplamente disseminado nas ciências sociais, é oportuno precisamente ao evocar estas fronteiras não bem constituídas ou que ficam com certos sombreamentos na relação entre Estado e sociedade. Particularmente, é precisamente o caráter aberto dessa relação que faz sentido sublinhar, mostrando que o Estado é capturado ou colonizado pelos atores por suas margens e que os espaços são disputados e reconfigurados a depender dos atores em jogo (BELEM, 2019). Esses espaços instáveis e disputados são

3 Sobre certos dilemas da relação entre poder e mediação entre agricultores ecologistas do sul do Brasil, ver Oliveira (2008). 
sempre preenchidos pelos que possuem poder de articular e traduzir demandas, efetivar ligações entre grupos sociais, projetos e organizações, realizar intervenções variadas. Por esta razão nem sempre serão as entidades do Estado a concretizarem a mediação; nem mesmo pode-se afirmar que organizações da sociedade civil serão as substitutas do Estado de modo permanente, esse preenchimento do espaço é contingente.

\section{O Estado e as ambivalências: sedação e sedução nas políticas de desenvolvimento}

Pode-se estabelecer uma comparação inicial neste ponto do texto. Olhando-se agricultores ecológicos prestigiados da região e técnicos de instituições do Estado que de algum modo se vinculam à agroecologia, observa-se que está muito mais para a dinâmica dos primeiros a atividade de organização da circulação e disseminação dos saberes, enquanto para os últimos muitas vezes se coloca mais um trabalho de mediação em termos políticos (entre instituições). Isso revela a dinamicidade da mediação, porém importa destacar que há uma tentativa de simetrização dos conhecimentos, uma vez que, se os técnicos que participam das reuniões não se privam de demonstrar seus conhecimentos "acadêmicos", os atores do rural tampouco se mostram tímidos para falarem e serem reconhecidos (ainda que, como frisado, podem ser poucos os agricultores que realmente assim o fazem). Um dos argumentos a serem realçados neste artigo é justamente o fato de que o Estado tem porosidades e as ações dos atores sociais se processam numa trama de relações envolvendo-o, porém sempre aparecem avaliações a respeito da natureza das ações estatais. Esta malha de relações sociais configura de modo menos estático a mediação. Embora se afirme que isso coloca limites ao poder das instituições estatais, parte dos atores do Estado concretiza um número importante de ações com efeitos expressivos, compreendidos ora como positivos ora como negativos pelos agricultores. 
A ambivalência que apresentei no início deste texto esboça o desenho dessas relações complexas. Há que se considerar que o Estado é entendido como "benfeitor" quando abre oportunidades, coloca agentes públicos a favor dos agricultores, disponibiliza recursos e elabora boas políticas. Nesta senda, agricultores não veem nenhum grande dilema em se tornar parceiros das organizações estatais. É preciso considerar que a condição, muitas vezes, de subalternidade, que é histórica em algumas regiões, organiza tais avaliações acerca do Estado. Portanto, perder chances de fazer o Estado trabalhar para a agroecologia é algo visto como errôneo. Entretanto, esse mesmo Estado é responsável por atrapalhar, por vezes, por se intrometer em âmbito das associações e por tornar a vida mais "burocrática" em diferentes ocasiões. É aqui que a sensação fica eventualmente indefinida, pois ora vemos uma coisa, ora outra. O excesso de intrusão é problemático, e na agricultura ecológica tem ocorrido muito, conforme os entrevistados me falaram.

Como compreender esses processos? Tanto repulsa como fascínio aparecem e seus semblantes não deixam dúvidas ao me contarem as situações vividas, especialmente as experiências coletivas em associações, cooperativas e organismos da sociedade civil em prol da agroecologia.

Ao longo da pesquisa, escutei que seria tarefa principal do Estado conduzir políticas favoráveis aos agricultores ecológicos. Isso se organizaria de diversas formas, tais como auxiliar na conversão à agroecologia e melhorar canais de comércio. Mas o que realmente ouvi foi a cantilena da ação burocrática e as instituições estatais sempre mais devagar que o andamento da sociedade. Evidentemente, esta personificação é uma curiosa maneira de falar do Estado, porque também aparece objetificado (algo separado das relações sociais).

Na época, um exemplo emblemático foi a reordenação dos sistemas de garantia na forma de certificação e esquemas participativos. Pela relevância do caso para a pesquisa, narro alguns dos detalhes. Entre 2007 e 2009, vários instrumentos foram colocados em marcha pelo Estado, concernentes à agroecologia, o que fez 
com que surgissem inúmeros selos, tornando o panorama bastante confuso ao consumidor. Considerando as legislações e selos estaduais e municipais, a inflação de selos era enorme. Entretanto o que mais complicou foi a reorganização nos seus términos, pois, a partir de então, o que antes era tacitamente compreendido enquanto certificação participativa se tornava sistema participativo de garantia. Foi sutil, porém não pouco importante tal inflexão. A reflexão a fazer é que tipo de desconstrução isso operaria, haja vista que foram elas, as certificações participativas, que iniciaram todos os processos de certificação no Brasil. Além disso, o novo sistema obrigava determinados controles contábeis e administrativos que encareciam o trabalho das associações e também tornavam as organizações obrigatoriamente abertas a auditorias. Esse foi um momento de clara intrusão e desconstituição do trabalho feito nas bases. Mesmo mais recentemente, quando se tornou mais evidente a tentativa de simplificação das certificações - tanto os fluxos como o entendimento por parte da sociedade (IFOAM, 2007) - com o Sistema Brasileiro de Avaliação da Conformidade Orgânica, um dos problemas passou a ser o modo como ele altera determinadas práticas que estavam alicerçadas e construídas, inclusive na relação de confiança estabelecida por parte de consumidores com as redes vis-a-vis o sistema oficial.

Muita gente, mesmo assim, concordou que a partir daquele momento haveria maior visibilidade para a agroecologia. Vários observaram que a questão se dava também em torno do quanto o Estado prestava atenção no assunto - ou seja, para as ciências sociais o tema caro da questão da agenda em políticas e igualmente a discussão sobre ação pública - e isto poderia dar legitimidade às formas sustentáveis de produção. É claro que pesquisas mais recentes têm mostrado que não se trata somente do Estado nesta intricada relação, particularmente com a criação e legitimação de dispositivos de governo e normalização. Niederle e Radomsky (2017) demonstraram a ampla gama de articulações entre corporações, Estados e diferentes atores (com diversos interesses no 
cenário global) nos ramos alimentares e de normatização, que convergem para organização de formas potentes de governo.

À medida que me defrontava em pesquisa de campo com os dilemas dos agricultores em relação ao Estado, percebi que alguns estudos recentes de Giorgio Agamben (2002; 2004) poderiam elucidar elementos dessa ambiguidade. Agamben (2002) mostra que o fundamento originário da política ocidental não está na democracia da cidade grega antiga, modelo tornado emblemático da autonomia política humana e da participação através da palavra. Esse berço potencialmente modelador do pensamento político moderno encontra outros elementos a confrontá-lo. O poder sempre foi categoria vinculada ao controle do limiar da ordem política - quem está sob o mando do soberano, do Estado. O poder como capacidade de decidir sobre o ordenamento jurídico-político envolve uma dupla dimensão: o terror da violência sobre o corpo social e a vontade, por parte daqueles que obedecem, de não estarem abandonados da proteção soberana (AGAMBEN, 2002; 2004; 2015).

Recupero os escritos de Agamben, buscando interpretar com certa margem de liberdade sua obra e a noção geral de que reside no Estado a autoridade acerca do limiar da ordem jurídico-política. Estar fora, excluído, pode significar ampla liberdade, mas também implica estar à mercê, abandonado. Aceitar a inclusão é também acatar o conjunto de imposições, coerções, normas e benefícios. Se os atores consideram o Estado moroso e impessoal nas suas ações, além de sempre ter o poder de intrusão ou banimento, é também o Estado que oferece condições propícias. Se as sentenças "quase não há apoio" ou "não há coordenação nenhuma" eram sempre repetidas em campo quando os agricultores analisavam o Estado, também se percebia nessa ausência o medo do excesso de intrusão ou da lentidão quando conseguiam algo; igualmente, o problema girava em torno do núcleo de que, sim, queriam apoio, cobiçavam ações efetivas. Algo foi feito ao longo da história recente da agroecologia do oeste de Santa Catarina e, tomando somente o caso dos entes vinculados ao Estado, muitos processos 
colocados em movimento partiram de sujeitos isolados dentro das organizações estatais que acreditaram poder dar certo tais iniciativas (o que significou ter que acreditar nas ações e experiências dos próprios agricultores e ecologistas). Foi só com o tempo e com um longo processo de mobilização de mediação pacienciosa que os quadros majoritários se tornaram mais ativos. Ao final, muitas das iniciativas relativas à agroecologia (tais como as feiras de Chapecó) foram chanceladas por leis municipais e outros mecanismos. Isto é, sem as lutas dos atores da sociedade e a posterior aceitação formal no interior do Estado nada aconteceria.

Outra dimensão que chama a atenção na pesquisa de campo é a relação que os grupos da Ecovida na região estabelecem com a Epagri (Empresa de pesquisa agropecuária e extensão rural do estado de Santa Catarina). Ainda que seja a instituição mais compromissada com a construção, em parcerias com agricultores, de melhores condições para o desenvolvimento da agroecologia, os técnicos reconhecem que fazem atividades limitadas: o quadro voltado ao tema é reduzido e os recursos são direcionados a outras áreas em que a empresa atua. Como instância de caráter público, naqueles anos em que fiz pesquisa em Chapecó, a Epagri organizou iniciativas junto aos agricultores ecológicos para criarem um banco de sementes livres, isto é, que não estivessem protegidas por regimes de direitos intelectuais. A intenção era originar variedades para serem colocadas à disposição para os agricultores. Mas entre os atores do meio rural emergiu uma questão interessante: se, por um lado, a cooperação da Epagri com eles era extensa e importante, por outro, deixar que as sementes permanecessem somente sob o controle do Estado poderia ser perigoso. Os agricultores sustentavam que eles próprios deveriam ser guardiões e guardiãs (BENVEGNU, 2017) de sementes e que era fundamental que a empresa pública fizesse sua parte enquanto eles fariam a parte deles, ou seja, buscariam sementes quase perdidas, manteriam e preservariam em suas propriedades as variedades cultivadas. Apesar dessas relações, que podem demonstrar orientações distintas, os grupos de agricultores e a Epagri conservam a aliança e a parceria 
As políticas de desenvolvimento entre a sedução e a sedação

Guilherme Francisco Waterloo Radomsky

com a intenção de obter os benefícios, alegando, ainda assim, que deixar o controle genético totalmente nas mãos da Empresa não Ihes interessa.

As sementes, sabe-se, são fundamentais na agricultura, então a questão sobre quem detém controles genéticos é de suma importância. Porém, não somente isso se apresenta. Em entrevista durante a pesquisa, fui recordado que os sistemas financeiros e de crédito também avaliam sementes. Em geral, no Brasil, o crédito na agricultura é ofertado principalmente por bancos do Estado ou com capital do Estado. Mas ocorre que, para que o crédito seja concedido, os cultivos podem ser aprovados ou reprovados. Quando os agricultores querem plantar sementes livres, tais como as que mencionei anteriormente, os bancos podem avaliar como "tecnologia inapropriada". Não sendo variedades melhoradas por empresas de biotecnologia, as sementes livres (também chamadas de crioulas) podem ser mais arriscadas em termos de perdas. Mas, em muitas situações, os agricultores não atestam tal problema. Assim, acaba sendo bastante fácil compreender esse processo como uma forma de veto que é dado pelo próprio Estado (embora aqui com articulações com as empresas de biotecnologias), portanto adicionando mais alguns elementos a respeito da ambivalência das ações do Estado que antes apresentei ${ }^{4}$.

Por esta razão, retorno a Agamben (2004) e sua intenção em examinar as relações intrínsecas entre ordem jurídica, poder e violência: a instituição da ordem jamais escapa da violência pela qual ela se funda e se mantém no exercício da soberania estatal. Nessa interpretação, Agamben (2004) realiza uma dupla leitura sobre poder-violência e como entender o tempo presente por meio das proposições tanto de Benjamin como de Foucault (1999), apesar das distâncias teóricas entre estes autores. Presente no texto clássico de Benjamin (1986)5 , a relação entre direito, poder e violência é central. Essa problemática se desdobra num campo

\footnotetext{
4 Em trabalho sobre sementes no Brasil meridional, Benvegnu (2017) sustentou que problemas também ocorrem na medida em que variedades transgênicas passam a ser largamente utilizadas e agricultores estimulados direta ou indiretamente a abandonar sementes crioulas. Após vários anos, a promessa de produtividade dos transgênicos se confronta com sua diminuição progressiva e aumento substancial dos custos de produção.

5 Sobre esse assunto, veja também Seligman-Silva (2006)
} 
em que gravitam as noções de desejo e repulsa pelas intervenções do Estado, pois estar abandonado, sem apoio, pode-se configurar num problema também grave.

Voltando ao curso de eventos e relações colocados em prática pelos atores depois deste breve parêntese teórico, outros problemas se apresentam nesse contexto. O Estado, tal como já referi em passagem anterior, não é somente esse monstro que impede a ação e coloca problemas ao burocratizar a vida das pessoas. É até fascinante ver que mais e mais características negativas surgem nas falas sobre o Estado, mais cobrança por parte dos atores aparecem. Darci, que foi um dos mais frequentes interlocutores que mantive em campo, certa vez afirmou:

O poder público teria que ter ação primordial para a agroecologia. Isto porque o consumidor e o agricultor trabalham e não podem ir a tantas reuniões. O Estado deveria deslocar pessoas especificamente para a agroecologia, técnicos de campo. É preciso haver programas e projetos para conversão das propriedades, com assessoria e garantia de mercado.

Ao longo desse diálogo, continuava me falando das possibilidades e necessidades dos agricultores e, principalmente, como a prefeitura da cidade deveria trabalhar para o grupo - no sentido de que o Estado seria o ator primordial a fazer coisas pela sociedade. Na semana seguinte, quando voltei a Ihe encontrar, como de costume, na feira do centro de Chapecó, Darci me disse com certa confiança que conseguira fazer com que o poder local começasse um diálogo com o coletivo da Ecovida regional. Com otimismo, referiu-se ao fato ventilado de que a prefeitura poderia vir a disponibilizar um técnico para acompanhar exclusivamente a agroecologia. "O Estado dando apoio e o agricultor conseguindo vender, a agroecologia anda", falou com esperança. Naquele dia, proporcionou uma precisa avaliação sobre as relações conjunturais e dos sistemas de poder que incidem na agricultura ecológica: 
O Estado não tem vontade de fazer andar a agroecologia, porque os grupos dos "grandes" são fortes e barram essas iniciativas. O Estado prefere estimular um agricultor que vende apenas leite e em grande quantidade do que auxiliar na diversificação e no beneficiamento, em produtos agroecológicos com mais valor econômico. Para o Estado, não se ganha com isso, quem não ganha é o Estado, pois terá mais trabalho, o agricultor certamente ganha.

A esta altura deve estar transparente para o leitor que a noção de desenvolvimento colocada em movimento pela máquina estatal de intervenção não equipara, de modo algum, desenvolvimento com bem-estar, expansão das liberdades ou aumento da qualidade de vida. Ao Estado é imputado o papel histórico de construir políticas sobre o social, categoria que passa a ser objeto das intervenções para que o social possa operar e se dinamizar através de ações econômicas. Quero sugerir a expressão máquina antipolítica e providencial, observando o dispositivo que captura a vida (DELEUZE e GUATTARI, 2012; FERGUSON, 1990), despolitizando o problema do desenvolvimento (para torná-lo um problema técnico) e que promete providência via governo das pessoas (conduzindo as condutas), eventualmente fazendo uso da violência ou da ação normalizadora sobre esta mesma vida. Concretamente, pensar o desenvolvimento como uma máquina providencial não requer que sempre se considerem suas políticas e programas como pretensas produtoras de bem-estar ou benefícios à sociedade. A providência é encapsuladora, ela pode prometer e não realizar; providenciar é também sustentar que se pode geralmente recorrer a ações de transformação social "em nome do desenvolvimento" e que, todavia, muitas vezes se constituem como verdadeiros empecilhos ou princípios desorganizadores da vida de grupos sociais. Realizar projetos quaisquer (mineração, hidrelétricas e outras, só para citar exemplos de grandes obras) "em nome do desenvolvimento" é simplesmente usar o artifício da providência como meio de ofuscar e engazopar. Argumentos e iniciativas liberais ou neoliberais, por esta razão, cabem bem - especialmente no Brasil - no discurso 
As políticas de desenvolvimento entre a sedução e a sedação

do desenvolvimento, mesmo que sejam termos eventualmente considerados contraditórios.

Neste sentido, seguindo alguns estudos críticos sobre poder e desenvolvimento (PERROT, 2008; KINGSBURY 2013; FIGUEIRÓ 2018), a perspectiva do que seja o desenvolvimento neste trabalho não consiste num eterno caminhar da humanidade para melhores formas de viver; é, antes, um conjunto ordenado de políticas que visam à mudança social num ambiente, geralmente - não exclusivamente - exercido por agentes externos.

A "era do desenvolvimento" (usualmente entendida pela literatura como o período pós-1945), quando se inauguram todos os aparelhos de promoção das políticas (Banco Mundial, BID e outros), quando também a modernização da agropecuária entra num período de radicais transformações, é marcada pela atuação dos Estados como promotores, financiadores e condutores principais das mudanças desejadas para uma população.

A linhagem interpretativa, que vai de Benjamin (1986) a Agamben (2002), sugere tensões e conflitos no modo como Estado e desenvolvimento se articulam, jogando luz sobre a questão da (in) decisão soberana. O percurso possui um platô em Foucault (1999; 2008), que faz uma conexão entre governo e biopolítica. A noção de que a biopolítica exerce poderes no todo social não é estranha. Se, conforme Agamben (2002), a biopolítica consiste na inscrição crescente da vida biológica humana na ordem política, controlar e administrar pessoas (corpos e mentes) como um poder que deseja preservar a vida também se orienta para uma moldura do tipo de vida e de sujeito desejado (produtivo, racional, individualista, disciplinado, responsável). Parfitt (2009) comenta essa relação ao propor que em Agamben (2002) o tema do desenvolvimento aparece, ainda que brevemente, na forma de uma obsessão para produzir um povo indiviso (SYLVESTER, 2006).

Num livro muito profícuo que adere relativamente bem ao tema abordado aqui, Taussig (1992) discorre a respeito da atração que o Estado exerce sobre os indivíduos. Tal atração, para o au- 
tor, confunde-se com encanto e facilmente se transmuta em descontentamento, em um tipo de mescla e indecisão entre fascínio sedutor e repulsa, tema abordado também em Taussig (1997). É a obra de Benjamin que inspira o antropólogo quanto ao problema, já que o autor alemão havia argumentado como se traveste de mistério e mística a relação constituída com a ordem jurídica, a notar pelos seus escritos sobre a violência mítica que instaura e conserva o direito e também pelas relações complexas entre teologia, religião e política (BUTLER, 2006; BARBOSA, 2013; AGAMBEN, 2011).

Contudo, essa violência é igualmente aquela que inclui o poder do Estado (soberano), para o qual a sedução dos programas e políticas de desenvolvimento exerce incrível efeito no imaginário coletivo. Seria possível argumentar que a promessa do desenvolvimento encapsula os sujeitos menos como aprisionados numa armadilha e mais como o sonho do progresso e do reconhecimento social? O que não deixaria de ser um modo de aprisionamento que se vale da libido. O trecho a seguir é ilustrativo da relação entre estética e poder numa versão diferente das análises de Foucault:

O poder crítico do corpo empático é "estético" no sentido original do termo. O corpo pode sentir quando as razões se tornam racionalização e cultura é um eufemismo para opressão. [...] Disto segue que a ideologia precisa agir diretamente sobre os sentidos do corpo para conter seu potencial de rebelião. Ela faz isto não somente por meio de técnicas disciplinares (medo da punição ou da internalização de constrangimentos sociais), mas também através de sedação e sedução do poder cognitivo do corpo (BUCK-MORSS, 2000, p. 257, tradução nossa).

O ensaio de Benjamin (1986) finaliza com o problema da violência que estaria fora da ordem jurídico-política. A vida, administrada e normalizada, coincidindo com o direito, poderia ser superada. Uma versão de certo modo redentora, quiçá divina (RUIZ, 2012; SELIGMAN-SILVA, 2006). Butler (2006) observa que Benjamin (1986) se apoia na ideia de um imperativo não coercitivo, abrindo 
As políticas de desenvolvimento entre a sedução e a sedação

espaço para uma orientação ética de abertura e responsabilidade que destituiria a violência. Buscar os elementos de Benjamin para pensar Estado, soberania e violência pode substituir a análise pela escatologia, objetivo que não persigo neste trabalho. O que importa em termos analíticos é o dilema entre medo, repulsa, esperança e atração do Estado.

\section{Considerações finais}

A pesquisa que deu origem a este trabalho mostra que, entre agricultores ecológicos, o Estado se apresenta como uma entidade que é recorrentemente cobrada para formular e implementar políticas e programas de desenvolvimento rural, particularmente para promoção da agroecologia na região do oeste catarinense. A relação entre os atores e as organizações do Estado é constante e emergem diálogos profícuos, tensões e dilemas de decisão sobre como acionar o aparato. Os agricultores consideram que o ente estatal possui capacidade de financiar, articular, elaborar melhorias para agricultura orgânica, por esta razão fazem uso de estratégias variadas para envolver e pressionar, para serem visibilizados e apoiados. Quanto mais normativas e orientações para agroecologia, maior é a sensação de institucionalização e apoio.

Por outro lado, se na mesma medida se entende que maior visibilidade e institucionalização significam também melhores condições para oportunidades, as mesmas normativas, leis e ações públicas podem ter efeitos contraditórios, já que abrem a possibilidade de imposição de regras de produção, comercialização e certificação. Tornou-se evidente que, com as normas e regramentos, o setor se fortaleceu e concedeu também grande poder ao Estado para fiscalizar as estruturas dos organismos certificadores, verificar procedimentos de avaliação locais, estabelecer auditorias e controles antes não existentes. 
Tal ambiguidade parece captar a maneira como os atores se veem diante da relação com o Estado e com as políticas de desenvolvimento, uma vez que geralmente é o ente estatal o porta-voz e protagonista de programas e projetos para intervenção e transformação societária. O argumento principal é que nem se pode assumir que os agricultores ecológicos do oeste de Santa Catarina rejeitam a participação do Estado em suas vidas, nem concluir que simplesmente desejam irrestritamente sua tendência de poder de ação, justamente por se apresentar como lento, ambíguo e desarticulado. As políticas de desenvolvimento, pode-se dizer, oferecem sedução e encantamento simultaneamente às técnicas de governo/administração e à sedação que exerce.

Os fluxos de poder não são unidirecionais e é preciso ocupar os espaços de poder e resistência, insurgências veladas e agências propositivas, que são também capazes de instituir projetos e caminhos (alternativos ou convencionais) para o desenvolvimento. Destaca-se a atuação de mediadores, pois é justamente neste espaço de interface Estado-Sociedade, outsiders-insiders, organizações estatais-pessoas que emergem espaços para a ação e relações de poder - e a teoria sociológica recente observa o tema da mediação e da corretagem como elo para o debate teórico entre os níveis micro e macrossociológicos (STOVEL e SHAW, 2012) - aqui empiricamente descritos e examinados. Nesses espaços intersticiais é que cabe observar, primeiro, em que medida mediadores são agentes capazes de suprir demandas, agir a partir das margens e ocuparem determinados espaços, criando, a partir de relações de poder, condições de articulação entre grupos e entidades. Segundo, como o Estado se apresenta nos processos de desenvolvimento e, mesmo com a atuação intermitente dos mediadores, exerce um poder sobre a sociedade, que interpreta as intervenções de modo ambivalente e sujeitas a críticas. 
As políticas de desenvolvimento entre a sedução e a sedação Guilherme Francisco Waterloo Radomsky

\section{Referências}

agamben, Giorgio. Homo Sacer: o poder soberano e a vida nua I. Belo HORIZONTE: EdITORA DA UFMG, 2002.

AgAmben, Giorgio. Estado de exceção. 2a. ed. São Paulo: Boitempo, 2004.

AGAMBEN, Giorgio. O sacramento da linguagem: arQueologia do juRamento (Homo Sacer II, 3). Belo Horizonte: Editora da UFMG, 2011.

aGAMBen, Giorgio. Meios sem fim: notas sobre a política. Belo HORIZONTE: AUTÊNTICA, 2015.

ASSis, Renato Linhares; ROMEiro, Ademar Ribeiro. Agroecologia e agricultura orgânica: controvérsias e tendênCias. Desenvolvimento e Meio

Ambiente, N. 6, P. 67-80, 2002.

BARBOSA, Jonnefer. A crítica da ViolênCIA de Walter Benjamin: ImplicaçÕes histórico-temporais do conceito de reine Gewalt. Revista de Filosofia Aurora (UFPR), v. 25, N. 37, P. 151-169, 2013.

BARNES, John. Redes SOCIAIS E PROCESSO POLítico. In: FELDMAN-BIANCO, Bela. (Org.). Antropologia das sociedades contemporâneas: mÉtodos. São Paulo: Global, 1987. P. 159-193.

\section{BELEM, Regis. C. A construção da CATEgoria Agricultura familiar no}

Mercosul: um estudo a partir dos casos do Brasil e da Argentina. Porto Alegre, 2019. Tese (Doutorado em Desenvolvimento Rural). Universidade Federal do Rio Grande do Sul, Porto Alegre, 2019.

Benjamin, Walter. Crítica da Violência. Crítica do Poder. In: Benjamin, Walter. Documentos de Cultura, Documentos de Barbárie. (Vol. org. por Willi Bolle), SÃo Paulo: Cultrix, EDUSP, 1986. P. 160-175.

BENVEGNU, Vinícius. As sementes do lugar: política local e desenVolvimento rural no Rio Grande do Sul meridional. Porto Alegre, 2017. Dissertação (Mestrado em Desenvolvimento Rural) - Universidade Federal do Rıo Grande do Sul. 
As políticas de desenvolvimento entre a sedução e a sedação Guilherme Francisco Waterloo Radomsky

BUCK-MORSS, Susan. Dreamworld and catastrophe: the passing of Mass utopia in East and West. Cambridge, MA; London: Mit Press, 2000.

BUTLER, Judith. Critique, coercion, and sacred life in Benjamin's "Critique of Violence". In: DE VRies, Hent; SUllivan, Lawrence. (Ed.). Political THEOLOGIES: PUBLIC RELIGIONS IN A POST-SECULAR WORLD. FORDHAM UNIVERSITY PRESS, 2006. P. 201-219.

DAWSEY, John. Piscadela das caveiras: a escatologia do Jardim das Flores. Tempo Social, v. 19, N. 2, P. 179-202, 2007.

DeleuZe, Gilles; GUATTARI, Felix. Mil Platôs: capitalismo e esquizofreNiA, 2 (Vol. 5). 2 ed. São Paulo: Ed. 34, 2012.

DE VRIES, Pieter. VANishing Mediators: ENJOYMENT AS A POLITICAL FACTOR IN Western Mexico. American Ethnologist, v. 29, N. 4, P. 901-927, 2002.

DAS, Veena; POOle, Deborah. (Eds.). Anthropology in the Margins of the State. Santa Fe: School of American Research Press, 2004.

DODieR, Nicolas. Agir em diversos mundos. In: CARVAlHO, Maria do Carmo Brandt de. (Org.). Teorias da ação em debate. São Paulo: Cortez, FAPESP, PUC, 1993. P. 77-109.

FERGUSON, James. The anti-Politics machine: "DeVelopment”, Depoliticization, and bureaucratic power in Lesotho. Cambridge; New York: Cambridge UNIVERSITY PRESS, 1990.

Figueiró, lucas Woltmann. From USA, with love: desenvolvimento, extensão rural e gênero. Porto Alegre, 2018. Dissertação (Mestrado em Desenvolvimento Rural) - Universidade Federal do Rıo Grande do Sul.

Foucault, Michel. Em defesa da sociedade. Curso no Collège de France (1975-1976). São Paulo, Martins Fontes, 1999.

foucault, Michel. Segurança, território, população. Curso Collège de France (1977-1978). São Paulo: Martins Fontes, 2008.

GOLDMAN, Marcio. OS TAMBORES DO ANTROPÓlOGO: ANTROPOlOGIA PÓS-SOCial e etnografia. PontoUrbe, v. 3.0, 2008 disponível em: http://N-A-U.org/ pontourbe03/Goldman.html. Acesso em: 08 dez. 2009. 
As políticas de desenvolvimento entre a sedução e a sedação Guilherme Francisco Waterloo Radomsky

GOULDNER, Alvin Ward. The nORM of ReCIPROCITY: A PRELIMINARY StATEMENT. IN: SCHIMDT, Stephen et Al. (Ed.). Friends, followers and factions: a REAder IN political CLIeNtelism. Berkeley: University of CAlifornia Press, 1977. P. 28-43. IFOAM. SISTEMAS DE GARANTíA PARTICIPATIVOS: VISION COMPARTIDA, IDEALES COMPARTIDOS. IFOAM. 2007. DISPONÍVEL EM: HTTP://WWW.IFOAM.ORG/ABOUT_IFOAM/STANDARDS/PGS.HTML . ACESSO EM: 18 MAI. 2009.

Kingsbury, Damien. Critical reflections on development. New York: PALGRAVE, 2013.

MAYER, AdRIAN. A IMPORTÂNCIA DOS “QUASE GRUPOS” NO ESTUDO DAS SOCIEDADES COMPLEXAS. In: FELDMAN-BIANCO, Bela. (Org.). Antropologia das SocieDAdes CONTEMPORÂNeAs: MÉTOdOS. São PAUlO: Global, 1987. P. 127-158.

MEDEIROS, Monique; MARQUES, Flavia CharÃo. DoIS MUNDOS, DUAS LINGUAGENS: OS PROCESSOS DE MEDIAÇÃO SOCIAL E A DIVERSIDADE DE CONHECIMENTOS NA CONSTRUÇÃO DE PROJETOS PARA O DESENVOLVIMENTO RURAL. INTERTHESIS, V. 9, Р. 243-259, 2012.

MiOR, luis Carlos. Agricultores Familiares, agroindústrias e redes de desenvolvimento rural. Chapecó: Editora Argos, 2005.

NeVES, Delma Pessanha. Mediação social e mediadores políticos. In: NEVES, Delma Pessanha. (Org.) Desenvolvimento social e mediadores políticos. Porto Alegre: Editora da UFRGS, 2008. p. 21-44.

NIEDERLE, PAulo; RADOMSKY, GUILHeRme. Quem GOVERNA POR DISPOSITIVOS? A PRODUÇ̃̃O DAS NORMAS E PADRÕES PARA OS ALIMENTOS ORGÂNICOS NO BRASIL. ToMo, N. 30, P.227-265, JAN.-JUN., 2017.

OLIVEIRA, Valter LuCIO. "USANdo máscara e fazendo VISTA GROSSA": A AgRICULTURA ECOlÓGICA E SUA DIMENSÃO MORAL. ReVISTA IDEAS: INTERFACES EM DESENVolvimento, AGRICULTURA E SOCIEDADE, v. 2, N. 1, P. 32-52, JAN-JUN, 2008.

PARfitt, Trevor. Are the Third World poor Homines Sacri? Biopolitics, sovereignty, And deVelopment. Alternatives, N. 34, P. 41-58, 2009.

PERROT, Dominique. Quem IMPEDE O DESENVOLVIMENTO “CIRCULAR"? (Desenvolvimento e povos autóctones: paradoxos e alternativas). Cadernos de CAMpo, São Paulo, N. 17, P. 219-232, 2008. 
As políticas de desenvolvimento entre a sedução e a sedação Guilherme Francisco Waterloo Radomsky

ROVER, Oscar José. Redes de POder E GOVERNANÇA Local: ANÁLISE DA GESTÃo POLÍTICO-ADMINISTRATIVA EM TRÊS FÓRUNS DE DESENVOLVIMENTO COM ATUAÇÃO na Região Oeste de Santa Catarina/Brasil. 2007. Tese (Doutorado em Desenvolvimento Rural). Universidade Federal do Rio Grande do Sul, Porto Alegre, 2007.

RUIZ, Castor Bartolomé. A sacralidade da vida na exCeÇão soberana, A

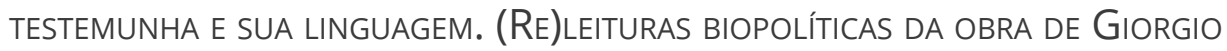
Agamben. Cadernos IHU, ano 10, N. 39, p.1-50, 2012.

SARDAN, Jean Pierre Olivier de. Anthropologie et developpment: essai en socio-Anthropologie du changement social. Paris: APAD/Karthala, 1995.

SEligMAN-SilVA, Marcio. Walter Benjamin: o Estado de exceção entre o político e o estético. Outra Travessia, n. 5, P. 25-38, 2006.

SEYFerTH, Giralda. Imigração e cultura no Brasil. Brasília: Ed. da UNB, 1990.

StOVEl, Katherine; ShaW, Lynnete. Brokerage. Annual Review of Sociology, v. 38, P. 139-158, 2012.

SILVERMAN, SYdel. THE COMMUNITY-NATION MEDIATOR IN TRADITIONAL CENtral Italy. In: POTTER, Jack; DIAZ, May; FOSTER, George. (Ed.) Peasant Society: a Reader. Boston: Little Brown, 1967. p. 279-293.

SpivaK, Gayatri Chakravorti. Pode o subalterno falar? Belo Horizonte: EDITORA DA UFMG, 2010.

SYLVESTER, Christine. Bare life AS a deVELopment/PostColonial PROBLEMATIC. The Geographical Journal, v. 172, N. 1, p. 66-77, 2006.

TAUSSiG, Michael. The nervous system. New York; London: Routledge, 1992. taussig, Michael. The magic of state. New York: Routledge, 1997. Velho, Gilberto; KuSChniR, Karina. Mediação e metamorfose. Mana: ESTUDOS DE ANTROPOLOGIA SOCIAL, V. 2, N. 1, P. 97-108, 1996.

VIVEIROS DE CASTRO, EduARdo. ExChanging PERSPeCtives: the tRansformation of objects into subjects in Amerindian ontology. Common

Knowledge, v. 10, N. 3, P. 463-484, 2004. 
As políticas de desenvolvimento entre a sedução e a sedação

Guilherme Francisco Waterloo Radomsky

WOLF, ERIC Robert. Aspectos das relações de GRUPo em UMA SOCIEDAde CompleXA: MÉxico. In: FELDMAN-BIANCO, Bela; RIBEIRO, Gustavo Luis. (Org.). Antropologia e poder: contribuições de Eric R. Wolf. BrasílaA: Ed. da UnB; São Paulo: Imprensa oficial do Estado de São Paulo: Ed. da UNICAMP, 2003. P. 73-91. 